\title{
Extensive aortic repair in acute aortic dissection: Not much bang for the buck?
}

\author{
Joon Bum Kim, MD, $\mathrm{PhD}$
}

\footnotetext{
From the Department of Thoracic and Cardiovascular Surgery, Asan Medical Center, University of Ulsan College of Medicine, Seoul, South Korea.

Disclosures: Author has nothing to disclose with regard to commercial support.

Received for publication March 30, 2018; accepted for publication April 5, 2018; available ahead of print May 1, 2018.

Address for reprints: Joon Bum Kim, MD, PhD, Department of Thoracic and Cardiovascular Surgery, Asan Medical Center, University of Ulsan College of Medicine, 388-1 Pungnap-dong Songpa-gu, Seoul 138-736, South Korea (E-mail: jbkim1975@amc.seoul.k).

J Thorac Cardiovasc Surg 2018;156:949-50

$0022-5223 / \$ 36.00$

Copyright (C) 2018 by The American Association for Thoracic Surgery

https://doi.org/10.1016/j.jtcvs.2018.04.012
}

With improving quality of cardiovascular surgeries and perioperative care, it is undoubtedly true that treatment outcomes of acute type A aortic dissection (ATAAD) is improving, and super-excellent outcomes even with extensive aortic procedures are being increasingly reported. According to the drift of mounting evidence toward more aggressive procedures of ATAAD in recent publications by leading experts, one might feel more pressure to do so rather than undertaking more conservative proximal supracoronary aortic repair. In theory, more extensive aortic repair in ATAAD is likely to reduce risks of later aortic events and reintervention, which are charming points of such procedures.

Even in the current era, however, real-world data still show very high surgical mortality rate $(15 \%-20 \%)$ in ATAAD. ${ }^{1}$ Because of its rare incidence (1-3 per 100,000 person-years), such high mortality perhaps is because ATAAD is more often operated on by surgeons with limited experience in aortic surgery and referring these patients to high-volume centers might worsen the situation because of transfer-related mortality. ${ }^{2}$ In these regards, the strategy of "small surgery" to circumvent a life-threatening condition might still be valid and be more generalizable.

Along with the International Registry of Acute Aortic Dissection ${ }^{1}$ and German Registry for Acute Aortic Dissection Type $\mathrm{A}^{3}$ the Nordic Consortium for Acute Type A Aortic Dissection (NORCAAD) is one of the biggest registries on surgery for ATAAD, and now its second report, in this issue of The Journal of Thoracic and Cardiovascular Surgery, deals with the issue whether more extensive arch and root replacement might benefit patients with ATAAD. ${ }^{4}$ The NORCAAD is unique because it involves mainly small- to medium-volume centers, which might give the insight into the management outcomes best reflective of the real-world practices. The early mortality rate of $17.6 \%$ revealed in their previous study shows how risky it still is to manage ATAAD. ${ }^{5}$ In general, surgical strategies of a reoperation.

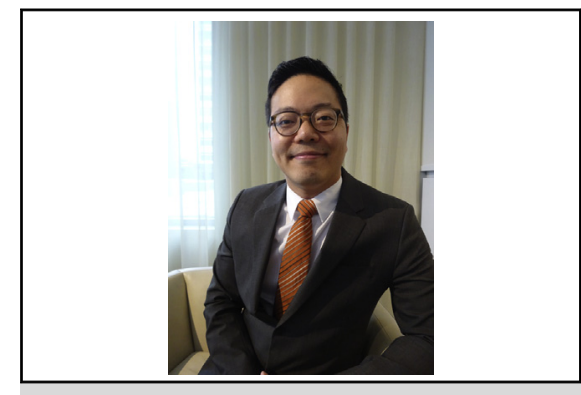

Joon Bum Kim, MD, PhD

Central Message

With improving quality of cardiovascular surgeries and perioperative care, it is undoubtedly true that treatment outcomes of acute type A aortic dissection are improving.

See Article page 939.

in the NORCAAD registry seem relatively conservative because only $5.7 \%$ of patients (66 of 1159 ) received total arch replacement, and even in the presence of connective tissue disease only $52.3 \%$ (28 of 53) and $15.1 \%$ (8 of 53) received root replacement and total arch replacement, respectively. ${ }^{4}$ As a result, freedom from root reoperation depending on concomitant root replacement did not differ (at 8 years, $97.4 \%$ vs $93.8 \% ; P=.84$ ) as were for freedom from distal reoperation depending on more extensive arch repair (at 8 years, $95.3 \%$ vs $92.4 \% ; P=.22$ ). The multivariable competing risk model also confirmed that the extent of the distal or proximal repair was not associated with the risk

In contrast, the postoperative stroke rate was significantly higher with total arch replacement compared with ascending aortic or hemiarch repairs $(33 \%$ vs $18 \%$; $P=.010)$ indicating that the cost of a more aggressive approach is profound. These findings partially correlate with a previous meta-analysis, which evaluated the effect of the arch repair extent on outcomes in type A aortic dissection and showed higher surgical risk (mortality) with more extensive arch repair. ${ }^{6}$ In that cited study, however, late reoperation risk was significantly lower with total arch repair than more conservative repair. Of note, the presence of connective tissue disease was associated with almost a fivefold increment in the rate of proximal reoperation in the NORCAAD data, suggesting that more extensive repair is a reasonable option in these patients, which 
correlates well with a previous multi-center study on ATAAD surgery in Marfan syndrome.?

The current NORCAAD report also has limitations: (1) median follow-up time is only 2.7 years, which is not sufficient to make conclusions on comparative late outcomes, (2) selection bias is also an important issue because of the nonrandomized design, and (3) region-specific practice patterns might limit the generalizability. Despite these limitations, the NORCAAD again revealed important insights into real-world outcomes of ATAAD surgery, giving a word of caution on aggressive surgical approaches as a routine setting. Nevertheless, the question still lingers on whether the comparable freedom from reoperation will remain similar even in longer term follow-up. Also, it needs to be answered from further studies whether the comparative outcomes between the aggressive and conservative surgeries will differ depending on center or surgeon experiences.

\section{References}

1. Pape LA, Awais M, Woznicki EM, Suzuki T, Trimarchi S, Evangelista A, et al. Presentation, diagnosis, and outcomes of acute aortic dissection: 17-year trends from the international registry of acute aortic dissection. J Am Coll Cardiol. 2015;66:350-8

2. David TE. Surgery for acute type A aortic dissection. J Thorac Cardiovasc Surg. 2015:150:279-83.

3. Weigang E, Conzelmann LO, Kallenbach K, Dapunt O, Karck M. German registry for acute aortic dissection type A (GERAADA)-lessons learned from the registry. Thorac Cardiovasc Surg. 2010;58:154-8.

4. Emily Pan BM, Gudbjartsson T, Ahlsson A, Fuglsang S, Geirsson A, Hansson EC, et al. Low rate of reoperation after acute type A aortic dissection repair from the Nordic consortium registry. J Thorac Cardiovasc Surg. 2018;156:939-48.

5. Olsson C, Ahlsson A, Fuglsang S, Geirsson A, Gunn J, Hansson EC, et al. Medium-term survival after surgery for acute Type A aortic dissection is improving. Eur J Cardiothorac Surg. 2017;52:852-7.

6. Yan Y, Xu L, Zhang H, Xu ZY, Ding XY, Wang SW, et al. Proximal aortic repair versus extensive aortic repair in the treatment of acute type A aortic dissection: a meta-analysis. Eur J Cardiothorac Surg. 2016;49:1392-401.

7. Rylski B, Bavaria JE, Beyersdorf F, Branchetti E, Desai ND, Milewski RK, et al. Type A aortic dissection in Marfan syndrome: extent of initial surgery determines long-term outcome. Circulation. 2014;129:1381-6. 